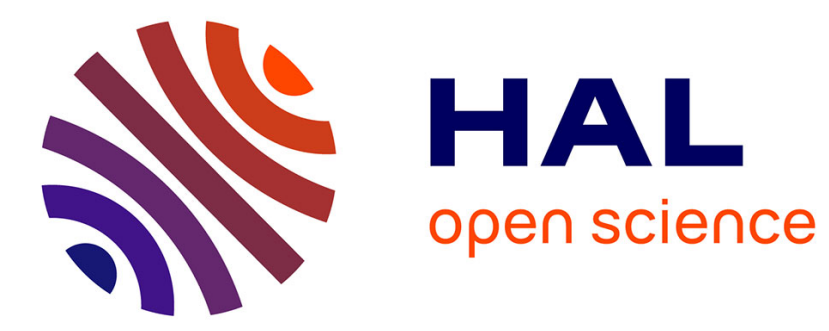

\title{
Multicatalytic Transformation of (Meth)acrylic Acids: a One-Pot Approach to Biobased Poly(meth)acrylates
} Hugo Fouilloux, Wei Qiang, Carine Robert, Vincent Placet, Christophe M Thomas

\section{- To cite this version:}

Hugo Fouilloux, Wei Qiang, Carine Robert, Vincent Placet, Christophe M Thomas. Multicatalytic Transformation of (Meth)acrylic Acids: a One-Pot Approach to Biobased Poly(meth)acrylates. Angewandte Chemie International Edition, 2021, 60 (35), pp.19374 - 19382. hal-03427031

\section{HAL Id: hal-03427031 https://hal.science/hal-03427031}

Submitted on 12 Nov 2021

HAL is a multi-disciplinary open access archive for the deposit and dissemination of scientific research documents, whether they are published or not. The documents may come from teaching and research institutions in France or abroad, or from public or private research centers.
L'archive ouverte pluridisciplinaire HAL, est destinée au dépôt et à la diffusion de documents scientifiques de niveau recherche, publiés ou non, émanant des établissements d'enseignement et de recherche français ou étrangers, des laboratoires publics ou privés. 

Approach to Biobased Poly(meth)acrylates

\author{
Hugo Fouilloux, Wei Qiang, Carine Robert, Vincent Placet, and Christophe M. Thomas*
}

\begin{abstract}
Shifting from petrochemical feedstocks to renewable resources can address some of the environmental issues associated with petrochemical extraction and make plastics production sustainable. Therefore, there is a growing interest in selective methods for transforming abundant renewable feedstocks into monomers suitable for polymer production. Reported herein are one-pot catalytic systems, that are active, productive, and selective under mild conditions for the synthesis of copolymers from renewable materials. Each system allows for anhydride formation, alcohol acylation and/or acid esterification, as well as polymerization of the formed (meth)acrylates, providing direct access to a new library of unique poly(meth)acrylates.
\end{abstract}

\section{Introduction}

Cheap, light and versatile plastics are the dominant materials of our modern economy. ${ }^{[1]}$ The vast majority of these commodity materials are obtained from fossil fuels. ${ }^{[2]}$ In order to remedy some of the environmental challenges associated with petrochemical extraction, an alternative to fossil feedstocks involves using chemicals from renewable resources. ${ }^{[3]}$ In particular, the development of new methods for transforming biomass into resources suitable for polymer production is a critical hurdle along the path to a more sustainable chemical economy. The main challenge is then to design efficient and selective transformations of abundant, renewable, low-cost raw materials into innovative polymeric products. ${ }^{[4]}$ Catalysis is as an important tool to support a more sustainable plastics production and in this case should ideally be efficient, convenient, and versatile, using common reagents. In this regard, one-pot catalytic transformations have significant advantages over conventional multi-step syntheses such as time- and cost-savings, waste reduction and energy consumption. $^{[5]}$ These synthetic schemes, which proceed through two or more consecutive catalytic steps, may serve as a versatile method in polymerization reactions, enabling the production of polymers with new structures and func-

[*] H. Fouilloux, Dr. W. Qiang, Dr. C. Robert, Prof. C. M. Thomas PSL University, Chimie ParisTech, CNRS, Institut de Recherche de Chimie Paris

75005 Paris (France)

E-mail: christophe.thomas@chimie-paristech.fr

Dr. V. Placet

FEMTO-ST Institute, CNRS/UFC/ENSMM/UTBM, Department of Applied Mechanics, Université de Bourgogne Franche-Comté Besançon (France)

(2) Supporting information and the ORCID identification number(s) for

the author(s) of this article can be found under:

https://doi.org/10.1002/anie.202106640. tions. ${ }^{[6]}$ However, the one-pot synthesis of a target (macro)molecule is not simply a linear combination of each optimized reaction. ${ }^{[7]}$ The different catalytic systems used must be compatible with each other but also with the solvent, substrate, and reaction side products in order to obtain high activity and selectivity. ${ }^{[8]} \mathrm{A}$ one-pot synthesis is thus not only a useful methodology to follow for the production of (macro)molecules, but also a promising green approach for polymer synthesis. ${ }^{[9]}$

Poly(meth)acrylates are a major class of commodity plastics. ${ }^{[10]}$ Numerous studies have led to the discovery of multiple commercial applications for poly(meth)acrylates ranging from functional coatings to energy storage materials, high-performance engineering plastics and biomaterials. ${ }^{[10 a, 11]}$ The diversity of pendent ester groups that can be inserted into the (meth)acrylic repeat unit is one of the features that allows poly(meth)acrylates to exhibit varied properties. Due to the vast number of alcohols that can act as precursors of (meth)acrylate ester monomers, the potential number of unique poly(meth)acrylates is large and only a small part of this extensive series of polymers has been investigated. This widely unexplored polymer library offers the possibility to identify original materials with interesting properties, particularly from renewable resources. Fully sustainable poly(meth)acrylates can nowadays theoretically be obtained by producing (meth)acrylic acid from renewable resources, ${ }^{[12]}$ efficiently coupling it with biobased alcohols, ${ }^{[13]}$ and polymerizing the resulting monomer. ${ }^{[14]}$ However, most research groups investigating the properties of biobased poly(meth)acrylates usually prepare their materials stepwise, starting from acryloyl chloride or methacrylic anhydride as these procedure require only a simple workup. ${ }^{[12]}$ Although one of the methods of choice for modifying poly(meth)acrylates properties remains copolymerization, no examples of copolymerization of (meth)acrylate derivatives from carboxylic acid precursors have yet been reported via a one-pot procedure. Herein we present a practical route to biobased poly(meth)acrylates by way of a one-pot reaction using simple commercial catalysts and we demonstrate that these requirements can be met using, inter alia, the synthesis of intermediate anhydride derivatives. This process provides direct access to (meth)acrylates and the corresponding (co)polymers in high yields. 
a)

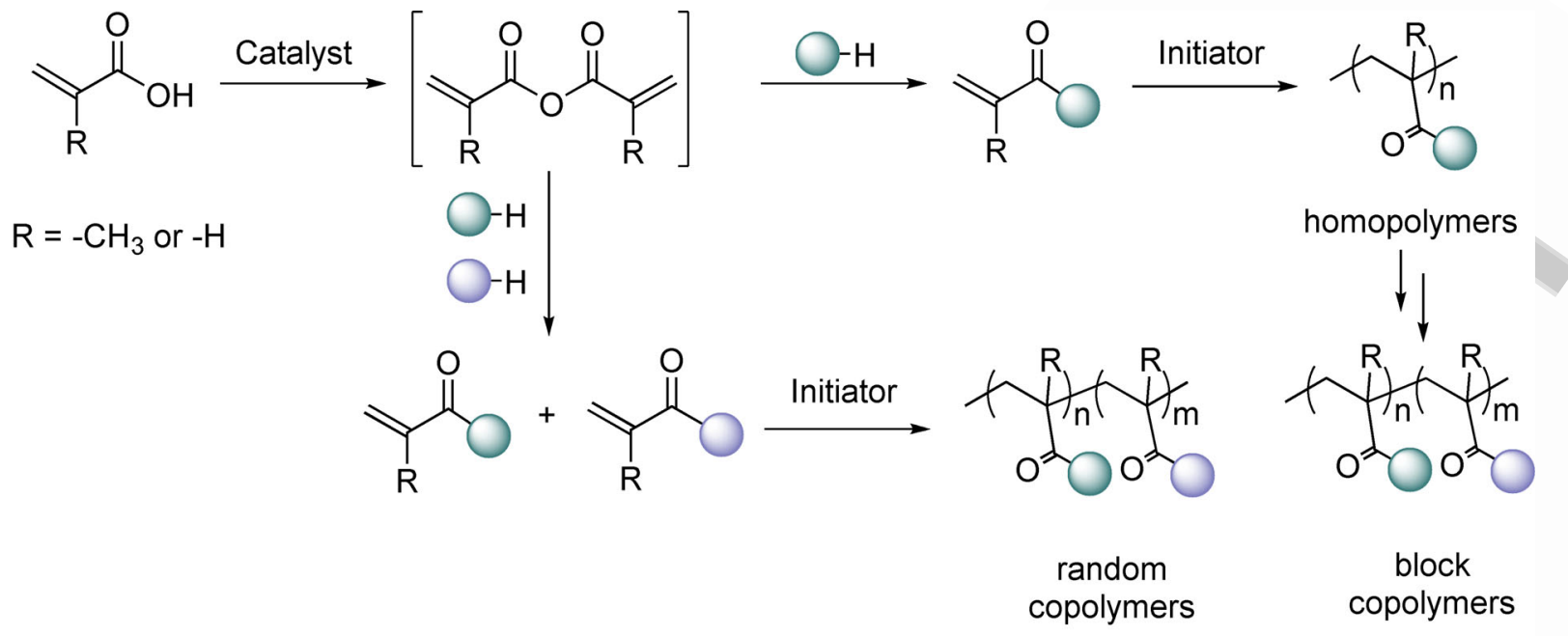

b)

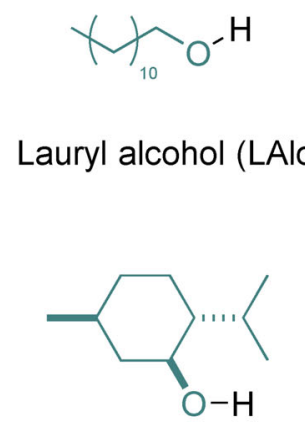

L-Menthol (LMn)<smiles>CC(C)CCCC(C)CCO</smiles>

Tetrahydrogeraniol (THG)<smiles>NCC1CCCO1</smiles>

Tetrahydrofurfuryl amine (THFA)<smiles>CCOC(=O)C(C)O</smiles>

Ethyl L-lactate (EL)<smiles>COc1ccc(C=O)cc1O</smiles>

Vanillin (Van)

Scheme 1. a) One-pot synthesis of (meth)acrylate copolymers from biobased alcohols and (meth)acrylic anhydride. b) Biobased building block scope demonstrating generality of the methodology.

\section{Results and Discussion}

\section{Monomer Formation Sequence}

Formation of (meth)acrylic anhydrides

In order to generate (meth)acrylate monomers directly ready for copolymerization, the first objective of our one-pot approach was the synthesis of (meth)acrylic anhydrides from (meth)acrylic acids, able to act as intermediates for the synthesis of one or more esters (Scheme 1). This reaction is a known transformation that can only be achieved by dehydration of the starting compound under acidic conditions and at high temperature. To complete a one-pot procedure, it is therefore necessary to have an anhydride synthesis process that is efficient and produces anhydrides with a high yield. We have recently reported effective protocols for the preparation of cyclic anhydrides from the reaction of dicarboxylic acids in the presence of dialkyl dicarbonates under weak Lewis acid (LA) catalysis. ${ }^{[6 a, 15]}$ Inspired by these previous results, it was envisaged that commercially available catalysts, such as magnesium chloride or triflate, could provide direct access to (meth)acrylic anhydrides with high selectivity and activity from the corresponding carboxylic acids. ${ }^{[16]}$
By reacting two equivalents of (meth)acrylic acid with ditert-butyl dicarbonate $\left(\mathrm{Boc}_{2} \mathrm{O}\right)$ and a suitable catalyst, it is indeed possible to obtain quantitatively acrylic or methacrylic anhydrides. For instance, the mild Lewis acid $\mathrm{MgCl}_{2}$ catalyzes selectively the formation of the anhydride within 20 minutes at $30^{\circ} \mathrm{C}$ (Table 1 , entries $1 \& 2$ ). Magnesium triflate proved to be much slower for this reaction, reaching full conversion after $18 \mathrm{~h}$ (Table 1, entry 3). Traces of tert-butyl methacrylate were also observed. This by-product formation becomes even more pronounced when using strong Lewis acids (Table S1), as observed with $\mathrm{La}(\mathrm{OTf})_{3}$ which cannot convert all the acid and only achieves $86 \%$ selectivity (Table 1 , entry 4 ).

\section{Acylation with anhydrides}

Encouraged by these first results, we investigated the next step of our one-pot approach: the acylation of a biobased alcohol with (meth)acrylic anhydride. We hypothesized that triflate complexes would have the potential to act as catalysts given their unique robustness and versatility, ${ }^{[17]}$ as well as their activity in the acylation of alcohol. ${ }^{[18]}$ The catalytic performances of different triflate complexes were therefore evaluated in the presence of commercially available alcohols and 
Table 1: Catalytic formation of (meth)acrylic anhydride with different catalysts. ${ }^{[a]}$

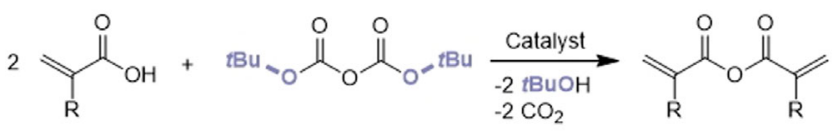

$\mathrm{R}=-\mathrm{CH}_{3}$ or $-\mathrm{H}$

\begin{tabular}{lcccc}
\hline Entry & Catalyst & Acid & $\begin{array}{c}\text { Acid Conversion } \\
\text { (Time) }\end{array}$ & $\begin{array}{c}\text { Selectivity } \\
{[\%]^{[b]}}\end{array}$ \\
\hline 1 & $\begin{array}{c}\mathrm{MgCl}_{2} \\
\left(4 \mathrm{~mol}^{\mathrm{b}}\right)\end{array}$ & Methacrylic & $100 \%(0.33 \mathrm{~h})$ & $>99$ \\
2 & $\begin{array}{c}\mathrm{MgCl}_{2} \\
(4 \mathrm{~mol} \%)\end{array}$ & Acrylic & $100 \%(0.33 \mathrm{~h})$ & $>99$ \\
3 & $\begin{array}{c}\mathrm{Mg}(\mathrm{OTf})_{2} \\
(4 \mathrm{~mol} \%) \\
4\end{array}$ & Methacrylic & $100 \%(18 \mathrm{~h})$ & 98 \\
& $\begin{array}{c}\mathrm{L}(\mathrm{OTf})_{3} \\
(0.5 \mathrm{~mol} \%)\end{array}$ & Methacrylic & $77 \%(7 \mathrm{~h})$ & 86 \\
\hline
\end{tabular}

[a] All reactions were performed under argon in acetonitrile, at $T=30^{\circ} \mathrm{C}$, with $[$ Acid $]=2 \times\left[\mathrm{Boc}_{2} \mathrm{O}\right]=3 \mathrm{~mol} \mathrm{~L}^{-1}$. [b] Selectivity was determined by ${ }^{7} \mathrm{H}$ NMR spectroscopy, calculating the integral ratio of the signals of the vinylic protons of (meth) acrylic anhydride and the by-product tert-butyl (meth) acrylate.

methacrylic anhydride. Representative results are summarized in Table 2.

We first investigated the use of strong Lewis acids as catalysts, such as scandium, yttrium and lanthanum triflate: the reaction of 50 equiv of methacrylic anhydride with lauryl alcohol was quantitative within 3,19 and $86 \mathrm{~h}$, respectively (Table 2, entries 1-3). This trend likely reflects the influence of the metal center Lewis acidity for rare-earth elements. ${ }^{[19]}$ Under the same reaction conditions, lauryl methacrylate was also obtained in the presence of mild Lewis acids such as magnesium triflate and magnesium chloride, but in lower

Table 2: Catalytic acylation of various alcohols/amine with different catalysts. ${ }^{[a]}$

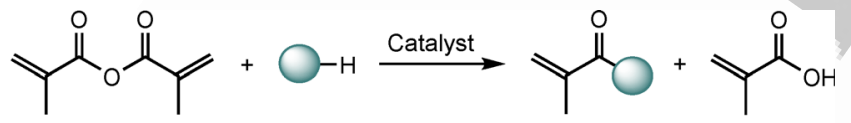

= bio-based alcohol or amine

\begin{tabular}{ccccc}
\hline Entry & Catalyst & Alcohol & Time $[\mathrm{h}]$ & Conversion [\%] $]^{[\mathrm{b}]}$ \\
\hline 1 & $\mathrm{Sc}(\mathrm{OTf})_{3}$ & Lauryl alcohol & 3 & 100 \\
2 & $\mathrm{Y}(\mathrm{OTf})_{3}$ & Lauryl alcohol & 19 & 100 \\
3 & $\mathrm{La}(\mathrm{OTf})_{3}$ & Lauryl alcohol & 86 & 100 \\
4 & ${\mathrm{Mg}(\mathrm{OTf})_{2}}$ & Lauryl alcohol & 120 & 86 \\
5 & $\mathrm{MgCl}_{2}$ & Lauryl alcohol & 120 & 95 \\
6 & $\mathrm{Y}(\mathrm{OTf})_{3}$ & Tetrahydrogeraniol & 20 & 100 \\
7 & $\mathrm{Y}(\mathrm{OTf})_{3}$ & L-Menthol & 39 & 100 \\
8 & $\mathrm{Y}(\mathrm{OTf})_{3}$ & Ethyl L-lactate & 72 & 100 \\
9 & $\mathrm{Y}(\mathrm{OTf})_{3}$ & Tetrahydrofurfuryl amine & 3 & 100 \\
$10^{[\mathrm{cc}}$ & $\mathrm{MgCl}_{2}$ & Tetrahydrogeraniol & 15 & 100 \\
\hline
\end{tabular}

[a] All reactions were performed under argon in acetonitrile, at $T=40^{\circ} \mathrm{C}$ with [Methacrylic Anhydride $]=[$ Alcohol $]=1 \mathrm{~mol} \mathrm{~L}^{-1}$ and a catalyst loading of $2 \mathrm{~mol} \%$. [b] Conversion was determined by ${ }^{1} \mathrm{H}$ NMR spectroscopy, calculating the integral ratio of the signals of the vinylic protons of methacrylic anhydride and the products formed. [c] From the reaction mixture of the anhydride formation step. After addition of THG, T was raised to $50^{\circ} \mathrm{C}$. yields (Table 2, entries 4\&5). Tetrahydrogeraniol, another primary biobased alcohol, was found as reactive as lauryl alcohol using yttrium triflate (Table 2, entry 6). Secondary alcohols, such as L-menthol and ethyl-L-lactate, could also be acylated (Table 2, entries $7 \& 8$ ), requiring a longer time than primary alcohols to give $100 \%$ of the corresponding biobased methacrylate, supposedly due to their lower nucleophilicity. This trend is confirmed by the faster acylation of amines, which are known to be better nucleophiles (Table 2, entry 9).

Finally, we were pleased to find that this acylation reaction can also be carried out from the reaction mixture of the previous anhydride formation step using $\mathrm{MgCl}_{2}$ (Table 2, entry 10). Increasing the temperature to $50^{\circ} \mathrm{C}$ in this second step even reduces the reaction time. Therefore, these results allowed us to confirm that the acylation of biobased alcohols/amine with (meth)acrylic anhydride can be carried out under mild conditions, is rapid in processing and suitable for the one-pot preparation of relevant methacrylate monomers.

\section{Esterification of (meth)acrylic acids}

We then studied the esterification of methacrylic acid using dimethyl dicarbonate $\left(\mathrm{Moc}_{2} \mathrm{O}\right)$ and $\mathrm{Boc}_{2} \mathrm{O}$ as coupling agents (Scheme 1). Based on the mechanism proposed by Bartoli, ${ }^{[20]}$ we assumed that the presence of a Lewis acid could cause the activation of the added dicarbonate, allowing the nucleophilic attack of the (meth)acrylic acid and ultimately leading to the formation of a mixed anhydride as a reaction intermediate (Figure 1). Then, the attack of a second (meth)acrylic acid generates the corresponding symmetrical anhydride, which can then react with the in situ released alcohol (i.e., methanol) in the case of $\mathrm{Moc}_{2} \mathrm{O}$, or with an alcohol more nucleophilic than $\mathrm{tBuOH}$ in the case of $\mathrm{Boc}_{2} \mathrm{O}$, as already observed in the acylation step.

As control experiments, scandium, yttrium and lanthanum triflate derivatives were first evaluated for the esterification of methacrylic acid with $\mathrm{Moc}_{2} \mathrm{O}$ (Table S2, entries 1-3): methyl methacrylate was the main product, with traces of dimethylcarbonate (Figure S1), as a result of the nucleophilic attack of the released methanol on the mixed anhydride intermediate or on $\mathrm{Moc}_{2} \mathrm{O}$ itself (vide infra). As the nonsequential addition did not lead to $100 \%$ conversion of methacrylic acid into MMA with neither of the catalysts studied, sequential addition of $\mathrm{Moc}_{2} \mathrm{O}$ was therefore performed in order to avoid the decomposition of the dicarbonate. Under these conditions, $\mathrm{Y}(\mathrm{OTf})_{3}$ was able to convert $100 \%$ of methacrylic acid into MMA within $4 \mathrm{~h}$ using a slight excess of $\mathrm{Moc}_{2} \mathrm{O}$ (Table 3, entry 1). For Sc(OTf) $)_{3}$ and La$(\mathrm{OTf})_{3}$ catalysts, a slightly higher excess of $\mathrm{Moc}_{2} \mathrm{O}$ (i.e., 1.5 equivalents with respect to methacrylic acid) is necessary to obtain quantitative yields (Table $\mathrm{S} 2$, entries $5 \& 6$ ).

In order to directly produce (meth)acrylates from the corresponding acid, we then investigated the use of $\mathrm{Boc}_{2} \mathrm{O}$ as a coupling agent (Table 3, entries 2-6). Gratifyingly, esterification of methacrylic acid by primary biobased alcohols such as lauryl alcohol or THG is efficiently and selectively carried out by $\mathrm{La}(\mathrm{OTf})_{3}$ and $\mathrm{MgCl}_{2}$, within 9 and $15 \mathrm{~h}$, respectively (Table 3, entries $2 \& 3)$. $\mathrm{Sc}(\mathrm{OTf})_{3}$ and $\mathrm{Y}(\mathrm{OTf})_{3}$ also catalyzed 
a)

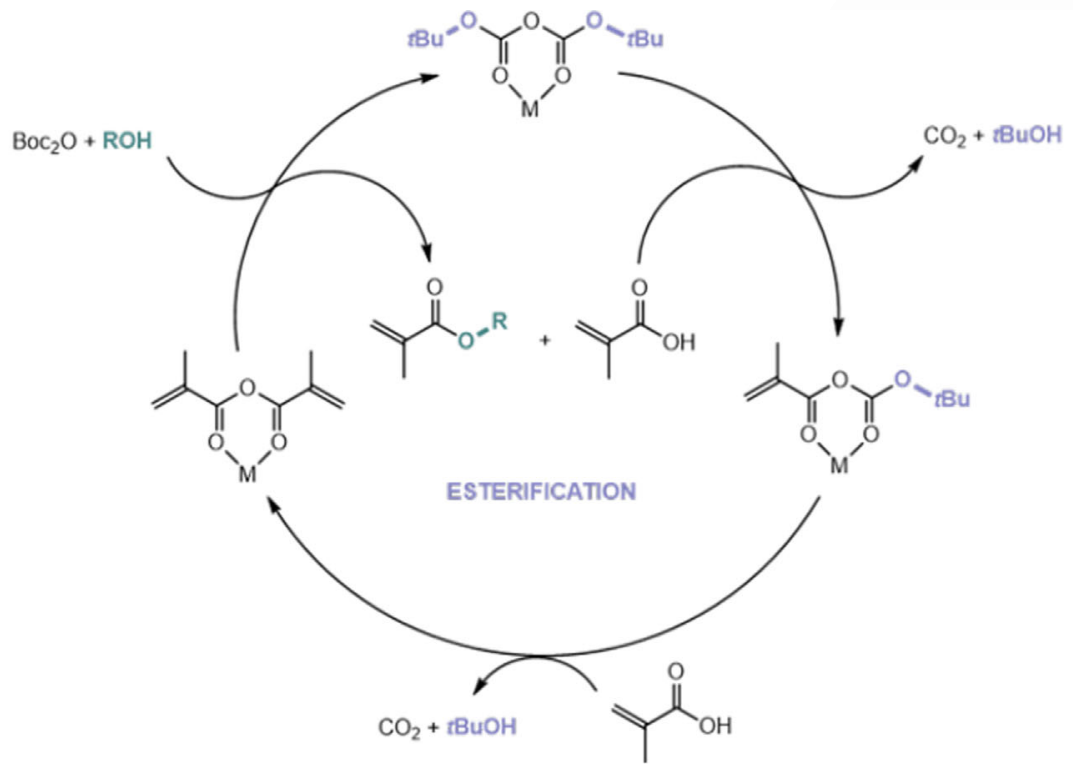

b)
$\delta_{\text {vinylic }}(p p m)=$
5,76
5,66
5,55<smiles>C=C(C)C(=O)OC(=O)C(=C)C</smiles><smiles>C=C(C)C(=O)OC(=O)O[13CH3]</smiles><smiles>C=C(C)C(=O)O</smiles><smiles>[R]OC(=O)C(=C)C</smiles>

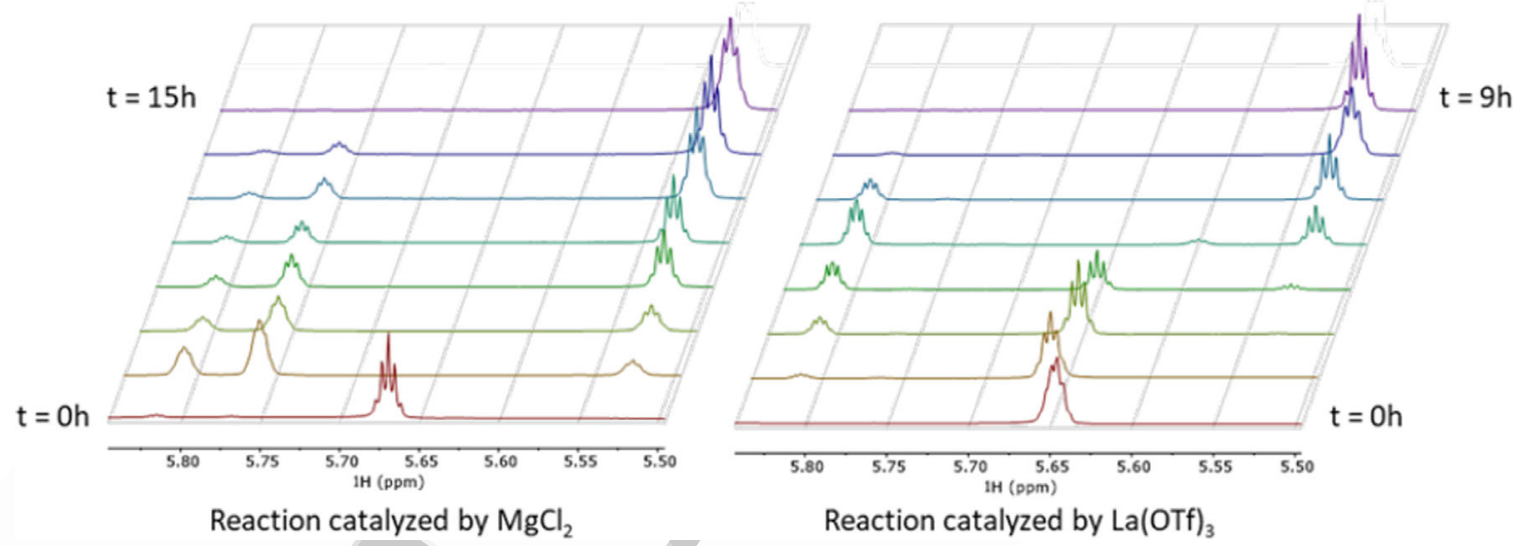

Figure 1. a) Envisaged mechanism for the esterification of methacrylic acid by an alcohol using $\mathrm{Boc}_{2} \mathrm{O}$, catalyzed by a metal-based complex $\mathrm{M}$; b) ${ }^{1} \mathrm{H}$ NMR monitoring $\left(400 \mathrm{MHz}, \mathrm{CDCl}_{3}, 20^{\circ} \mathrm{C}\right)$ of the reaction of methacrylic acid/tetrahydrogeraniol (1:1.2) with $\mathrm{MgCl}_{2}$ or $\mathrm{La}(\mathrm{OTf})_{3}$, using $\mathrm{Boc}_{2} \mathrm{O}$.

this reaction, although the selectivity was lower (ca. 97\%, Table S3, entries 1\&2). Acrylic acid is esterified under the same conditions, although it requires a longer reaction time for $\mathrm{La}(\mathrm{OTf})_{3}$ than $\mathrm{MgCl}_{2}$, with 87 and $15 \mathrm{~h}$, respectively (Table S3, entries $3 \& 4$ ). These two catalysts are in fact quite complementary to produce a diverse library of (meth)acrylates. On the one hand, $\mathrm{La}(\mathrm{OTf})_{3}$ is indeed more selective than $\mathrm{MgCl}_{2}$ for the esterification of MAA with bulky (and less reactive) secondary alcohols such as L-menthol (Table 3, entry 4 and Table S3, entry 5). On the other hand, $\mathrm{MgCl}_{2}$ is more functionally tolerant, as it could selectively produce methacrylates of ethyl-L-lactate and vanillin (Table 3, entries 5\&6). It should be noted that the use of a slight excess of alcohol and $\mathrm{Boc}_{2} \mathrm{O}$ (ca. $1.2 \times[$ Acid] $)$ is mandatory to achieve complete conversion of (meth)acrylic acid, as the secondary reaction involving an alcohol attacking the activated $\mathrm{Boc}_{2} \mathrm{O}$ to produce an unsymmetrical carbonate is observed to a small extent. Finally, although the use of amines in combination with $\mathrm{Boc}_{2} \mathrm{O}$ is unsuitable (Table $\mathrm{S} 3$, entry 6), our methodology however makes it possible to obtain methacrylamides together with another methacrylate, by first the reaction of the amine with the anhydride and then esterification of the remaining acid.

To verify the mechanistic pathway during the first three steps, we performed the ${ }^{1} \mathrm{H}$ NMR kinetic monitoring of the esterification of methacrylic acid by tetrahydrogeraniol, in the presence of $\mathrm{La}(\mathrm{OTf})_{3}$ or $\mathrm{MgCl}_{2}$ (Table 3, entries $2 \& 3$ ). The nature of the resulting intermediates was assessed by 
Table 3: Catalytic esterification of methacrylic acid with different alcohols, dicarbonates and catalysts. ${ }^{[a]}$

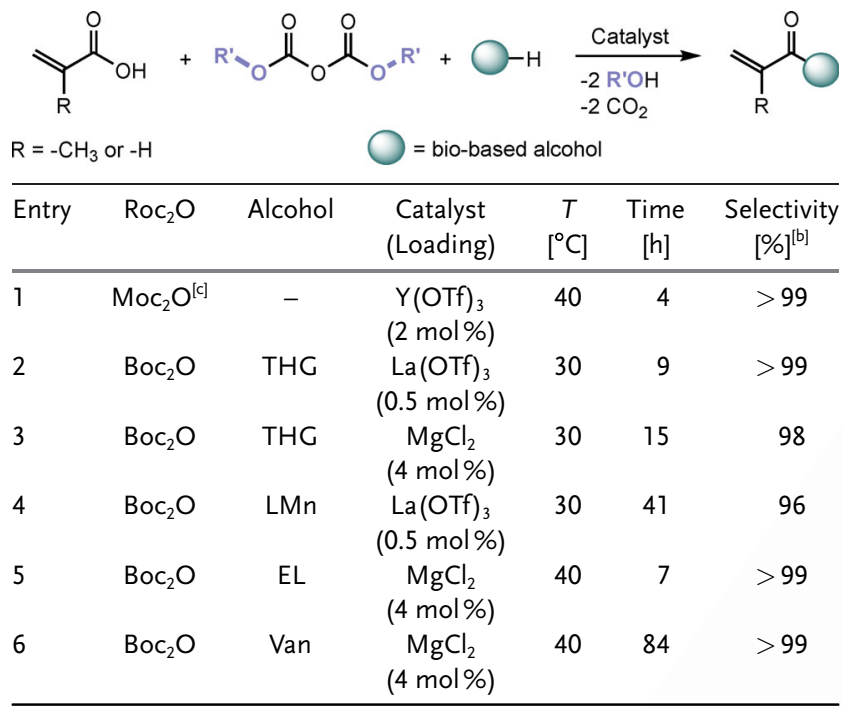

[a] All reactions were performed under argon in acetonitrile. [Methacrylic Acid $]=1.4 \mathrm{~mol} \mathrm{~L}^{-1}$ for entries 2 to 6 . $\left[\mathrm{Roc}_{2} \mathrm{O}\right]=[$ Alcohol $]=1.2 \times[$ Acid $]$ for all entries. [b] Selectivity of the corresponding methacrylate was determined by ${ }^{1} \mathrm{H}$ NMR spectroscopy, calculating the integral ratio of the signals of the vinylic protons of the methacrylates involved, methacrylic acid and methacrylic anhydride. [c] 1.2 equivalent of $\mathrm{Moc}_{2} \mathrm{O}$ with respect to methacrylic acid, added sequentially after the end of the first acylation step: 0.5 equivalents at $t=0,0.25$ equivalents at $t=0.5 \mathrm{~h}, 0.25$ equivalents at $t=1.5 \mathrm{~h}, 0.2$ equivalents at $t=3 \mathrm{~h}$.

\section{Polymer Formation Step}

With an efficient and quantitative synthesis of (meth)acrylates in hand, we then explored the radical polymerization of the resulting monomer mixtures using 2,2'-azobis(2methylpropionitrile) (AIBN) and various control agents. To assess the feasibility of the overall process, we conducted preliminary experiments with the rare earth triflate catalysts capable of performing the first two steps with a [catalyst]/ [AIBN] ratio of 2:1 (Table 4, entry 1 and Table S4, entries 1$3)$. We first tested the copolymerization of LMA with MMA. Indeed, these copolymers could be of great interest to industry, since the resulting poly(meth)acrylate will have "soft" (or low $T_{\mathrm{g}}$ ) segments of LMA associated with "hard" (higher $T_{\mathrm{g}}$ ) segments of MMA. Remarkably, all three one-pot systems were active for the polymerization step and exhibited comparable reactivities. Also, a similar experiment using $\mathrm{MgCl}_{2}$ for the monomer formation steps yielded comparable results (Table S4, entry 4). As a control experiment, we then performed a polymerization reaction using a clean combination of isolated methacrylates in the presence of AIBN (Table S4, entry 5). In marked contrast to what has been observed for other LA-mediated radical polymerizations of methacrylates, ${ }^{[21]}$ we noticed that direct polymerization gives poly(MMA-co-LMA) with a reactivity (i.e., molar masses and reaction rates) close to that obtained with one-pot systems. ${ }^{[22]}$ A conventional free radical pathway can also be suggested for these one-pot polymerizations, as the polymers obtained with

Table 4: Radical polymerization of various monomer mixtures with different control agents. ${ }^{[a]}$

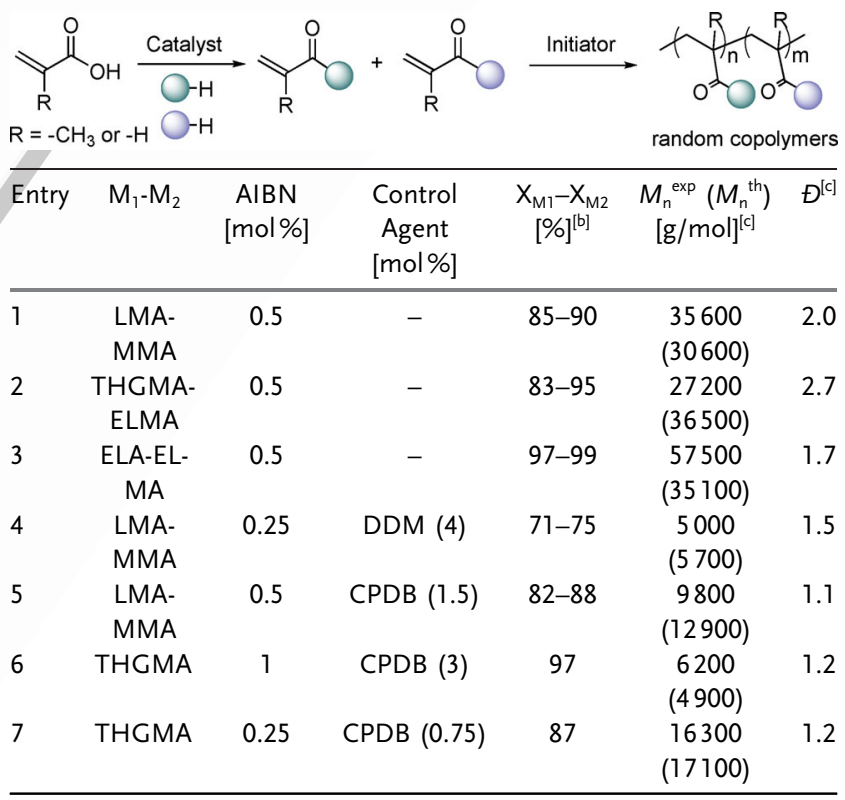

[a] All reactions were performed under Ar, adding to the previously prepared monomer mixture in acetonitrile a solution of AIBN in toluene $\left(\mathrm{V}_{\text {toluene }} / \mathrm{V}_{\mathrm{MeCN}}=3\right)$ and a control agent, and heating at $T=70^{\circ} \mathrm{C}$ for $20 \mathrm{~h}$. [b] Conversion was determined by ${ }^{7} \mathrm{H}$ NMR spectroscopy, calculating the integral ratio of the signals of the alkyl ester protons of the monomers and the polymers formed. [c] $M_{n}{ }^{\text {exp }}$ and $\emptyset$ of polymer determined by SEC$\mathrm{RI}$ in THF calibrated with polystyrene standards at $35^{\circ} \mathrm{C} . \mathrm{M}_{\mathrm{n}}^{\text {th }}$ : for detailed calculations see the Supporting information.

\section{These are not the final page numbers!}


LA/AIBN were syndiotactically-enriched (rr:rm:mm= 60:40:0), such as PMMAs prepared with AIBN in the literature. ${ }^{[23]}$ In addition, increasing the catalyst loading to $5 \mathrm{~mol} \%$ shows no significant difference (Table S4, entry 6). These results indicate that the active species formed during the (stepwise) copolymerization process might be the same species as that of the one-pot process, therefore suggesting that the coordination of a Lewis acid to the conjugate $-\mathrm{C}=\mathrm{O}$ electron-withdrawing group of either an alkene or radical is not effective. ${ }^{[21]}$ This lack of effect can be attributed to the presence of a Lewis base (e.g., traces of alcohol or dimethylcarbonate), that can compete with MMA and LMA for coordination to the Lewis acid. By varying the initiator loading, we were then able to obtain copolymers of different molar masses (Table S4, entries 7-9), with increasing dispersity as the amount of AIBN decreases. Various mixtures of comonomers could be randomly copolymerized, starting from one acid and two (or more) alcohols (Table 4, entry 2), or from one alcohol and acrylic and methacrylic acids (Table 4, entry 3). These examples illustrate the wide variety of combinations possible with a one-pot system.

In order to extend the versatility of our approach, we then decided to test the reactivity of different control agents and monomer mixtures for the polymerization step. ${ }^{[24]}$ A chain transfer agent, dodecyl mercaptan (DDM), and a RAFT agent, cyanopropyl dithiobenzoate (CPDB), were thus evaluated (Table 4, entries 4-7). ${ }^{[25]}$ These control agents were efficient in controlling the homo- and copolymerization process (predictable $M_{\mathrm{n}}$ and narrow $Ð$ ), with various molar masses accessible depending on the loadings of chain transfer agent and initiator. The evolution of $M_{\mathrm{n}}{ }^{\text {exp }}$ as a function of THGMA conversion was also assessed to show the control of the polymerization process using the RAFT agent (Figure S4). Overall, the radical polymerization process is efficient and not affected by the different byproducts of our onepot methodology.

Thanks to the ability of RAFT agent-capped polymers to act as macroinitiators, we then decided to explore the one-pot synthesis of block copolymers. We envisioned that, after an initial sequence of esterification $\left(30-40^{\circ} \mathrm{C}\right)$ and RAFT polymerization $\left(70^{\circ} \mathrm{C}\right)$, the reaction temperature could be reduced to $30-40^{\circ} \mathrm{C}$ and new reagents could be added to perform such a sequence again. The macroinitiator obtained upon the first sequence could then act as a RAFT agent and form block copolymers with the newly synthesized monomer (Table 5). This was first confirmed by the fact that the catalysts used for the initial sequence (i.e., $\mathrm{MgCl}_{2}$ or La$(\mathrm{OTf})_{3}$ ) were still active for a second esterification, in the same reaction mixture (Table S5). Slightly longer reaction times were required to achieve complete conversion, as the reaction medium was more diluted than under optimal conditions (Table 3). By increasing the reaction temperature again to $70^{\circ} \mathrm{C}$ after adding the initiator, we then successfully obtained block copolymers. Di-block copolymers of various compositions were accessible in two sequences, depending on the RAFT agent used (Table 5). Dithioesters such as CPDB were preferred for the copolymerization of methacrylates, while trithiocarbonates such as 2-(2-cyanoprop-2-yl)-S-dodecyltrithiocarbonate (CPDTC) provided a better balance between activity and control for acrylate polymerization. If a block copolymer of methacrylate and acrylate monomers is targeted, it is mandatory to use CPDTC and start with the poly(methacrylate) block (Table 5, entries 1-4), as the poly(methacrylate) chain is a better homolytic leaving group than the poly(acrylate) chain (Table 5, entries 5\&6). ${ }^{[26]}$ For the precise formation of blocks, it is crucial to attain near complete conversion of the first monomer before starting the synthesis of the second one. Depending on the monomers targeted, the catalyst must also be chosen carefully to obtain good selectivity in the esterification step. Notably, no change of molar mass was observed after the second esterification (Figures S5\&S6), meaning that the macroinitiator previously formed is inactive and unaffected under the conditions of the esterification step. As already reported by Perrier, some lowmolar mass tailings may appear after multiple polymerization steps, due to the accumulation of dead polymer chains, initiator-derived chains or possible interactions of the multiblock copolymer with the SEC column. ${ }^{[27]}$ As in all systems

Table 5: One-pot synthesis of various monomers and their block copolymerization. ${ }^{[a]}$

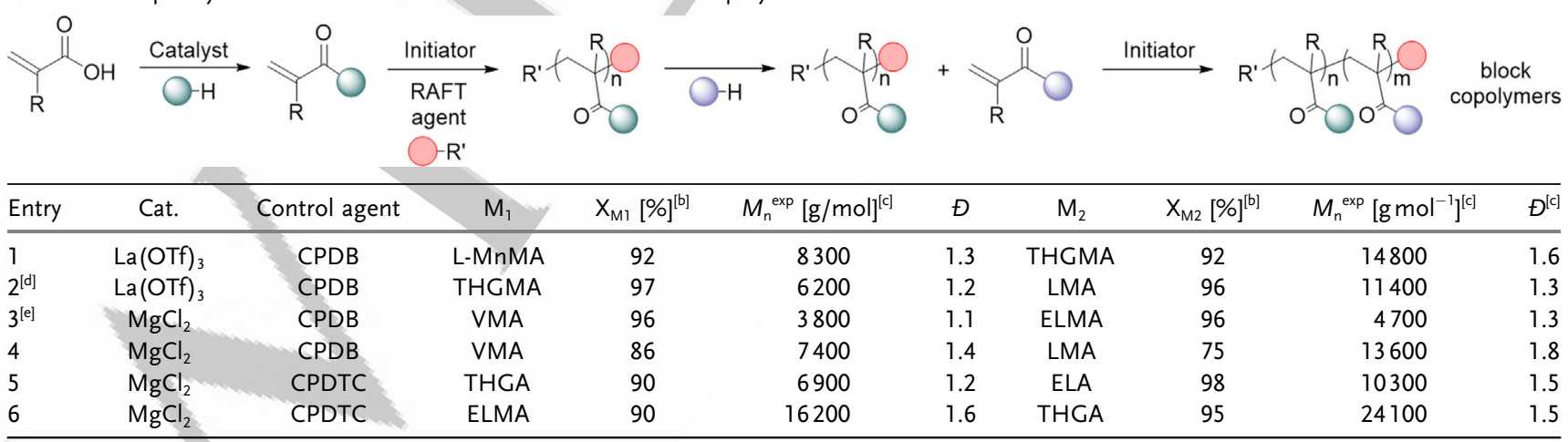

[a] All reactions were performed under $\mathrm{Ar}$, adding to the previously prepared monomer mixture in acetonitrile a solution of AIBN in toluene ( $\mathrm{V}_{\text {toluene/ }}$ $\mathrm{V}_{\mathrm{MeCN}}=3$ ) and a control agent ([Control agent] $/$ AIBN] $\left.=5\right)$, and heating at $T=70^{\circ} \mathrm{C}$ for $20 \mathrm{~h}$. Then, the reaction mixture was cooled back to 30 or $40^{\circ} \mathrm{C}$ (depending on the monomer) and (meth)acrylic acid, $\mathrm{Boc}_{2} \mathrm{O}$ and the desired alcohol were introduced (same ratios as in the 1 st step). Finally, after the desired amount of time, a solution of AIBN in toluene is added and the mixture is heated at $T=70^{\circ} \mathrm{C}$ for $20 \mathrm{~h}$. [b] Conversion was determined by ${ }^{1} \mathrm{H}$ NMR spectroscopy, calculating the integral ratio of the signals of the alkyl ester protons of the monomers and the polymers formed. [c] $M_{\mathrm{n}}$ exp and $Ð$ of polymer determined by SEC-RI in THF calibrated with polystyrene standards at $35^{\circ} \mathrm{C}$. [d] [Control agent]/ [AIBN] $=3$. [e] [Control agent]/ [AIBN] $=12$. 
based on a degenerative transfer mechanism, this can be avoided by using a higher [RAFT agent]/[initiator] ratio, as the number of living chains is dictated by the initial number of chain transfer agent. Finally, in order to determine topology and end groups of the copolymers, a diblock copolymer poly(VMA- $b$-ELMA) was characterized by MALDI-ToF-MS (Figures S7-S9). Analysis of the major isotope distributions confirmed the presence of the block copolymers with cyanopropyl and thiol end-groups. ${ }^{[28]}$

New homo- and copolymers synthesized by our one-pot process were then characterized by differential scanning calorimetry (DSC) and thermal gravimetric analysis (TGA) (Table $6 \&$ S6). The important range of $T_{\mathrm{g}}$ accessible confirms

Table 6: Thermal analyses of polymers obtained by one-pot catalysis. ${ }^{[a]}$

\begin{tabular}{lcrrrr}
\hline Entry & Type of (co)polymer & $\begin{array}{c}M_{\mathrm{n}} \text { exp } \\
{[\mathrm{g} / \mathrm{mol}]}\end{array}$ & $\begin{array}{r}T_{\mathrm{g} 1} \\
{\left[{ }^{\circ} \mathrm{C}\right]}\end{array}$ & $\begin{array}{c}T_{\mathrm{g} 2} \\
{\left[{ }^{\circ} \mathrm{C}\right]}\end{array}$ & $\begin{array}{r}T_{-5 \%} \\
{\left[{ }^{\circ} \mathrm{C}\right]}\end{array}$ \\
\hline 1 & poly(ELMA) & 43900 & 47 & - & 247 \\
2 & poly(THGA) & 25000 & -61 & - & 272 \\
3 & poly(THGMA) & 38300 & -27 & - & 214 \\
4 & poly(ELMA-r-MMA) & 37000 & 74 & - & 247 \\
5 & poly(ELMA- $r$-ELA) & 60300 & 27 & - & 310 \\
6 & poly(VMA- $b$-ELMA) & 21800 & 111 & 40 & 226 \\
7 & poly(ELMA- $b$-THGA) & 24100 & 40 & -50 & 291 \\
8 & poly(ELMA- $b$-THGMA- $b$-ELMA) & 22100 & 28 & -31 & 208 \\
\hline
\end{tabular}

[a] $M_{n}{ }^{\exp }$ of polymer determined by SEC-RI in THF calibrated with polystyrene standards at $35^{\circ} \mathrm{C}$. $T_{\mathrm{g}}$ of polymer determined by DSC on second heating cycle $\left(10^{\circ} \mathrm{C} / \mathrm{min}, \mathrm{N}_{2}\right.$ flow). $T_{-5 \%}$ of polymer determined by $\operatorname{TGA}\left(20^{\circ} \mathrm{C} / \mathrm{min}, \mathrm{N}_{2}\right.$ flow $)$.

the wide variety of characteristics that can be obtained using our synthetic method. Starting from acrylic acid, methacrylic acid or both, coupling it with various biobased alcohols (or amines) to obtain (random or block) homo- or copolymers, the possibilities are numerous. For instance, the homopolymer of ethyl-L-lactate methacrylate displays a $T_{\mathrm{g}}$ at $47^{\circ} \mathrm{C}$, while the homopolymer of tetrahydrogeraniol acrylate has a glass transition at $-61^{\circ} \mathrm{C}$, due to its more flexible side chain and the less rigid nature of the polyacrylate backbone (Table 6 , entries $1 \& 2$ ). The $T_{\mathrm{g}}$ of poly(ELMA) could either be increased or decreased by random copolymerization of ethyl-L-lactate methacrylate with other suitable comonomers (Table 6, entries 4\&5). Also, all of our di- and tri-block copolymers exhibited several glass transition temperatures, instead of a single $T_{\mathrm{g}}$ for fully miscible copolymers (Table 6 , entries 6 to 8) ${ }^{[29]}$ Interestingly, the significant increase in the glass transition temperature of the VMA-ELMA copolymer supports the hypothesis that the $T_{\mathrm{g}}$ of these copolymers is strongly dependent on their aromatic nature (Table 6, entry 6). In addition, the double bonds in these structures can provide a functional handle for subsequent modification or cross-linking of the material. For poly(ELMA-b-THGA), two glass transitions were observed at $-50^{\circ} \mathrm{C}$ and $40^{\circ} \mathrm{C}$ (Table 6 , entry 7). As compared to the $T_{\mathrm{g}} \mathrm{s}$ of poly(THGA) $\left(-61^{\circ} \mathrm{C}\right)$ and poly(ELMA) $\left(47^{\circ} \mathrm{C}\right)$ homopolymers, the small shifts indicate that the blocks of poly(THGA) and poly(ELMA) are only slightly miscible with each other. An increased thermal stability is observed for this copolymer when compared to poly(ELMA) and poly(THGA) (Figure S10). The block copolymer shows indeed a $5 \%$ weight-loss temperature of $291^{\circ} \mathrm{C}$, much higher than the ones of its respective homopolymers $\left(248^{\circ} \mathrm{C}\right.$ and $272^{\circ} \mathrm{C}$ for poly(ELMA) and poly(THGA), respectively). Such a synergy between these two blocks is noteworthy and provides better processability to the final material, as the operational window between the second glass transition temperature and the degradation temperature is expanded. The microphase separation was also confirmed for the triblock copolymer poly(ELMA- $b$-THGMA- $b$-ELMA), since two transitions are clearly observed, which are characteristic of the glass transition of the THGMA soft phase at the lower temperature $\left(-31^{\circ} \mathrm{C}\right)$ and the transition of the ELMA hard phase at a higher temperature $\left(28^{\circ} \mathrm{C}\right)$ (Table 6 , entry 8 ).

Remarkably, all homopolymers and random copolymers described in this study were colorless when using AIBN alone or AIBN and DDM as the initiating system. As expected, the RAFT agents used to synthesize the block copolymers imparted their color to the final material (yellow to pale yellow for CPDTC or pink to slightly orange for CPDB at low loadings, see Figure 2). If necessary, color removal is in principle feasible, as Perrier et al. reported an efficient method for end-group modification and chain transfer agent recovery from polymethacrylates synthesized by the RAFT process. ${ }^{[30]}$

Finally, the environmental impact of our one-pot methodology was quickly assessed by determining the E-factor of the overall synthesis and comparing it to existing literature. For instance, Epps and co-workers reported an elegant synthesis of a block copolymer of lauryl methacrylate and vanillin methacrylate, by RAFT polymerization, via a stepwise method. ${ }^{[31]}$ Their work was highlighted by the promising properties displayed by these new materials, but they also rightfully noted that the E-factor of their synthesis path could be improved (estimated at 500, which did not even include monomers synthesis). We could prepare a similar polymer (Table 5, entry 4) in one-pot fashion and estimated the Efactor of the overall process, including monomers synthesis, to approximately 150 (see Supporting information for detailed calculations). This dramatic decrease in mass intensity is due to the fact that workup solvents account for the major part of the total E-factor. Avoiding monomers and homopolymers isolation is therefore key for reducing the environmental impact of a synthesis path, a feature that is inherently accomplished by one-pot methodologies.

\section{Conclusion}

A new one-pot synthetic route for the production of (meth)acrylate monomers and the corresponding (co)polymers has been developed from renewable feedstocks. This approach makes it possible to directly obtain biobased materials in the form of homopolymers, or random or block copolymers, without needing to isolate and purify intermediates. In addition, these catalytic systems are remarkably robust, thus allowing the use of unpurified monomers and bench-top reaction setup. In this regard, the first steps can be performed under ambient air, although maintaining an inert atmosphere is essential for the control of the subsequent 

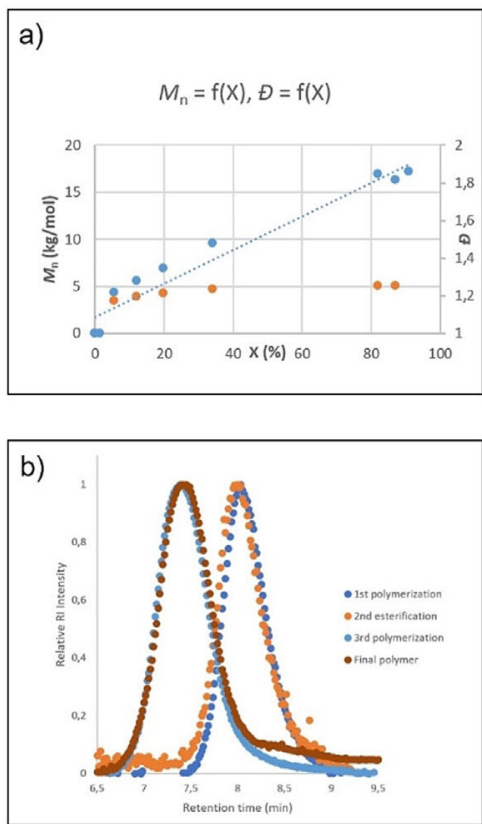

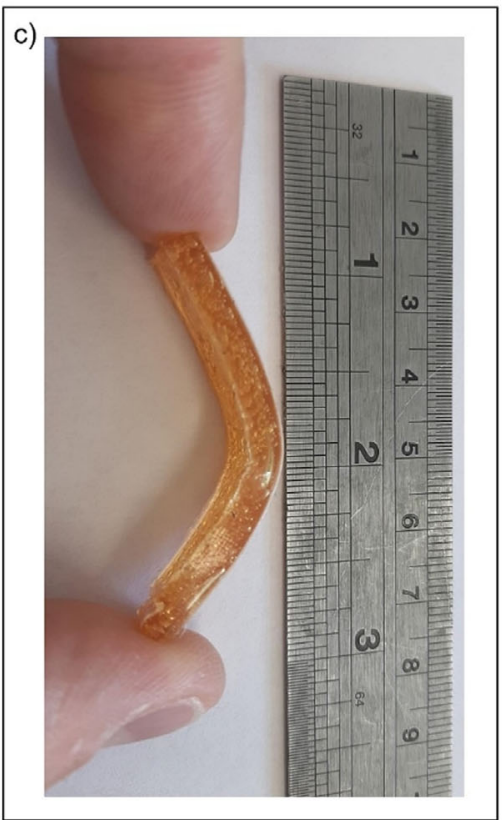

d)

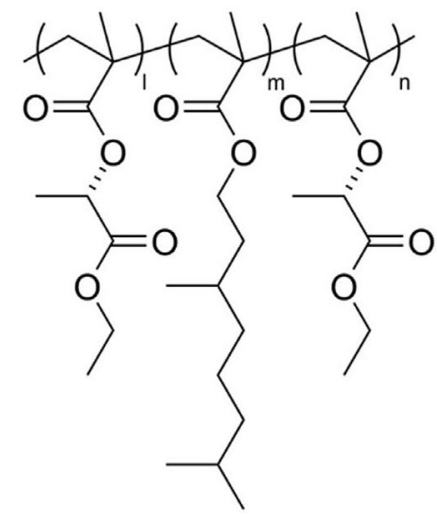

Figure 2. a) Evolution of $M_{n}$ (blue dots) and $\oslash$ (orange dots) versus the conversion of THGMA during its one-pot synthesis and polymerization using a RAFT agent. CPDB mol\% $=0.9$; AIBN mol\% $=0.09 . T=70^{\circ} \mathrm{C}$, for $46 \mathrm{~h}$. b) Evolution of the SEC-RI trace during the one-pot synthesis of the poly (ELMA-b-THGMA-b-ELMA) triblock copolymer (Table 6, entry 8), calibrated with polystyrene standards at $35^{\circ} \mathrm{C}$. c) Visual representation (photo) highlighting the elastomeric character of the poly(ELMA-b-THGMA-b-ELMA) triblock copolymer (Table 6, entry 8). Polymer sample manufactured by thermocompression using a hot press (see SI). d) Structure of the poly(ELMA-b-THGMA-b-ELMA) triblock copolymer (Table 6 , entry 8).

polymerization step. Ultimately, the strategy provides easy access to a set of unique macromolecular structures that can be used to meet the growing demand for new applications for commercial polymers. Our future efforts are oriented towards further study of the reaction mechanism, as well as development of catalysts that exhibit higher reactivities for the whole process.

\section{Acknowledgements}

CNRS and ENSCP are thanked for financial support. H.F. gratefully acknowledges financial support from École polytechnique (AMX) for his PhD scholarship. W.Q. acknowledges a fellowship from the CSC. Île-de-France Région is gratefully acknowledged for financial support of $500 \mathrm{MHz}$ NMR spectrometer of Chimie ParisTech in the framework of the SESAME equipment project. CMT is grateful to the Institut Universitaire de France.

\section{Conflict of Interest}

The authors declare no conflict of interest.

Keywords: (meth)acrylates · biobased polymers .

one-pot catalysis - reaction mechanisms - renewable monomers

[1] E. MacArthur, Science 2017, 358, 843.
[2] M. Okada, Prog. Polym. Sci. 2002, 27, 87-133.

[3] a) M. A. Hillmyer, Science 2017, 358, 868-870; b) M. Poliakoff, P. Licence, Nature 2007, 450, 810-812; c) A. J. Ragauskas, C. K. Williams, B. H. Davison, G. Britovsek, J. Cairney, C. A. Eckert, W. J. Frederick, Jr., J. P. Hallett, D. J. Leak, C. L. Liotta, J. R. Mielenz, R. Murphy, R. Templer, T. Tschaplinski, Science 2006, 311, 484-489; d) F. Seniha Güner, Y. Yağc1, A. Tuncer Erciyes, Prog. Polym. Sci. 2006, 31, 633-670; e) J. F. Jenck, F. Agterberg, M. J. Droescher, Green Chem. 2004, 6, 544-556; f) A. Corma, S. Iborra, A. Velty, Chem. Rev. 2007, 107, 2411-2502; g) U. Biermann, U. T. Bornscheuer, I. Feussner, M. A. R. Meier, J. O. Metzger, Angew. Chem. Int. Ed. 2021, https://doi.org/10. 1002/anie.202100778; Angew. Chem. 2021, https://doi.org/10. 1002/ange.202100778; h) L. A. Lucia, D. S. Argyropoulos, L. Adamopoulos, A. R. Gaspar, Can. J. Chem. 2006, 84, 960-970.

[4] a) P. B. Weisz, Phys. Today 2004, 57, 47-52; b) C. Williams, M. Hillmyer, Polym. Rev. 2008, 48, 1-10; c) M. J.-L. Tschan, E. Brulé, P. Haquette, C. M. Thomas, Polym. Chem. 2012, 3, 836851.

[5] a) D. E. Fogg, E. N. dos Santos, Coord. Chem. Rev. 2004, 248, 2365-2379; b) A. Ajamian, J. L. Gleason, Angew. Chem. Int. Ed. 2004, 43, 3754-3760; Angew. Chem. 2004, 116, 3842-3848; c) C. Robert, C. M. Thomas, Chem. Soc. Rev. 2013, 42, $9392-$ 9402.

[6] a) C. Robert, F. de Montigny, C. M. Thomas, Nat. Commun. 2011, 2, 586 םarticle number ok? $\square$; b) H. Lu, J. Wang, Y. Lin, J. Cheng, J. Am. Chem. Soc. 2009, 131, 13582-13583; c) M. Eriksson, A. Boyer, L. Sinigoi, M. Johansson, E. Malmström, K. Hult, S. Trey, M. Martinelle, J. Polym. Sci. Part A 2010, 48, 52895297; d) C. Cheng, K. Qi, E. Khoshdel, K. L. Wooley, J. Am. Chem. Soc. 2006, 128, 6808-6809; e) G. Chen, D. Huynh, P. L. Felgner, Z. Guan, J. Am. Chem. Soc. 2006, 128, 4298-4302; f) R. B. Grubbs, C. J. Hawker, J. Dao, J. M. J. Fréchet, Angew. Chem. Int. Ed. Engl. 1997, 36, 270-272; Angew. Chem. 1997, $109,261-264$ 
[7] a) Z. Jian, S. Mecking, Macromolecules 2016, 49, 4057-4066; b) E. W. Dunn, G. W. Coates, J. Am. Chem. Soc. 2010, 132, $11412-11413$; c) J.-C. Wasilke, S. J. Obrey, R. T. Baker, G. C. Bazan, Chem. Rev. 2005, 105, 1001-1020; d) S. K. Raman, E. Brulé, M. J.-L. Tschan, C. M. Thomas, Chem. Commun. 2014, 50 , 13773-13776; e) L. Fournier, C. Robert, S. Pourchet, A. Gonzalez, L. Williams, J. Prunet, C. M. Thomas, Polym. Chem. 2016, 7, 3700-3704; f) A. S. Goldman, Science 2006, 312, 257 261.

[8] a) S. L. Poe, M. Kobašlija, D. T. McQuade, J. Am. Chem. Soc. 2007, 129, 9216-9221; b) J. Zhou, Chem. Asian J. 2010, 5, 422 434.

[9] Y. Hayashi, Chem. Sci. 2016, 7, 866-880.

[10] a) P. F. Holmes, M. Bohrer, J. Kohn, Prog. Polym. Sci. 2008, 33 787-796; b) O. Nuyken, in Handbook of Polymer Synthesis CRC Press, Boca Raton, 2004, pp. 253-344; c) A. P. Mosley, in Brydson's Plastics Materials, Elsevier, Amsterdam, 2017, pp. 441-456; d) O. W. Webster in New Synthetic Methods, Vol. 167, Springer, Berlin, Heidelberg, 2003, pp. 1-34.

[11] a) M. J. Monteiro, M. F. Cunningham, Macromolecules 2012, 45 , 4939-4957; b) P. B. Zetterlund, S. C. Thickett, S. Perrier, E. Bourgeat-Lami, M. Lansalot, Chem. Rev. 2015, 115, 9745 -9800; c) M. Hong, J. Chen, E. Y.-X. Chen, Chem. Rev. 2018, 118, $10551-10616$

[12] H. Fouilloux, C. M. Thomas, Macromol. Rapid Commun. 2021, 42, 2000530

[13] M. A. Droesbeke, F. E. Du Prez, ACS Sustainable Chem. Eng. 2019, 7, 11633-11639.

[14] a) M. F. Sainz, J. A. Souto, D. Regentova, M. K. G. Johansson, S. T. Timhagen, D. J. Irvine, P. Buijsen, C. E. Koning, R. A Stockman, S. M. Howdle, Polym. Chem. 2016, 7, 2882-2887; b) R. L. Atkinson, O. Monaghan, M. T. Elsmore, P. D. Topham, D. T. W. Toolan, M. J. Derry, V. Taresco, R. Stockman, D. De Focatiis, D. J. Irvine, S. M. Howdle, Polym. Chem. 2021, 12, 3177-3189.

[15] C. Robert, F. de Montigny, C. M. Thomas, ACS Catal. 2014, 4, $3586-3589$.

[16] a) M. Carlsson, C. Habenicht, L. C. Kam, M. J. J. Antal, N. Bian, R. J. Cunningham, M. J. Jones, Ind. Eng. Chem. Res. 1994, 33, 1989-1996; b) J. Le Nôtre, S. C. M. Witte-van Dijk, J. van Haveren, E. L. Scott, J. P. M. Sanders, ChemSusChem 2014, 7, $2712-2720$; c) M. Pirmoradi, J. R. Kastner, ACS Sustainable Chem. Eng. 2017, 5, 1517-1527; d) D. W. Johnson, G. R. Eastham, M. Poliakoff, WO 2011/077140 A2, 2011.

[17] S. Kobayashi, M. Sugiura, H. Kitagawa, W. W.-L. Lam, Chem. Rev. 2002, 102, 2227-2302.

[18] a) K. Ishihara, M. Kubota, H. Kurihara, H. Yamamoto, J. Am. Chem. Soc. 1995, 117, 4413-4414; b) K. Ishihara, M. Kubota, H. Kurihara, H. Yamamoto, J. Org. Chem. 1996, 61, 4560-4567; c) K. K. Chauhan, C. G. Frost, I. Love, D. Waite, Synlett 1999,
1743 -1744; d) P. Saravanan, V. K. Singh, Tetrahedron Lett. 1999, 40, $2611-2614$; e) C.-T. Chen, J.-H. Kuo, C.-H. Li, N. B. Barhate, S.-W. Hon, T.-W. Li, S.-D. Chao, C.-C. Liu, Y.-C. Li, I.-H. Chang, J.-S. Lin, C.-J. Liu, Y.-C. Chou, Org. Lett. 2001, 3, 3729-3732; f) A. Orita, C. Tanahashi, A. Kakuda, J. Otera, J. Org. Chem. 2001, 66, 8926-8934.

[19] S. Fukuzumi, K. Ohkubo, Chem. Eur. J. 2000, 6, 4532-4535.

[20] G. Bartoli, M. Bosco, A. Carlone, R. Dalpozzo, E. Marcantoni, P. Melchiorre, L. Sambri, Synthesis 2007, 3489-3496.

[21] B. B. Noble, M. L. Coote, Adv. Phys. Org. Chem. 2015, 49, 189258.

[22] a) M. Imoto, T. Otsu, Y. Harada, Makromol. Chem. 1963, 65, 180-193; b) S. Okuzawa, H. Hirai, S. Makishima, J. Polym. Sci. A-1 Polym. Chem. 1969, 7, 1039-1053; c) Y. Isobe, T. Nakano, Y. Okamoto, J. Polym. Sci. Part A 2001, 39, 1463-1471.

[23] In a typical free radical polymerization, the stereoregulating effect results from a steric interaction between the incoming alkene and nearest stereocenter, but due to the conformational mobility of the chain, this effect is minimal: For example, the ratio of $k_{\mathrm{s}} / k_{\mathrm{i}}$, for methyl acrylate is 1.1 at $0^{\circ} \mathrm{C}$ : a) P. Pino, U. W. Suter, Polymer 1976, 17, 977 -995; b) T. Ando, M. Kamigaito, M. Sawamoto, Macromolecules 1997, 30, 4507-4510.

[24] a) J.-F. Lutz, M. Ouchi, D. R. Liu, M. Sawamoto, Science 2013, 341, 1238149; b) T. P. Le, G. Moad, E. Rizzardo, S. H. Thang, WO98/01478, 1998; c) J. Chiefari, Y. K. (Bill) Chong, F. Ercole, J. Krstina, J. Jeffery, T. P. T. Le, R. T. A. Mayadunne, G. F. Meijs, C. L. Moad, G. Moad, E. Rizzardo, S. H. Thang, Macromolecules 1998, 31, 5559-5562; d) K. Matyjaszewski, Macromolecules 2020, 53, 495 - 497; e) S. Perrier, Macromolecules 2017, 50, 7433 7447; f) M. Destarac, Polym. Chem. 2018, 9, 4947-4967.

[25] C. Barner-Kowollik, M. Buback, B. Charleux, M. L. Coote, M. Drache, T. Fukuda, A. Goto, B. Klumperman, A. B. Lowe, J. B. Mcleary, G. Moad, M. J. Monteiro, R. D. Sanderson, M. P. Tonge, P. Vana, J. Polym. Sci. Part A 2006, 44, 5809-5831.

[26] D. J. Keddie, Chem. Soc. Rev. 2014, 43, 496-506.

[27] G. Gody, T. Mashmeyer, P. B. Zetterlund, S. Perrier, Nat. Commun. 2013, 4, 2505. Darticle number ok?

[28] L. Charles, Mass Spectrom. Rev. 2014, 33, 523-543.

[29] T. G. Fox, Bull. Am. Phys. Soc. 1956, 1, 123-135.

[30] S. Perrier, P. Takolpuckdee, C. A. Mars, Macromolecules 2005, 38, 2033-2036.

[31] A. L. Holmberg, J. F. Stanzione III, R. P. Wool, T. H. Epps III, ACS Sustainable Chem. Eng. 2014, 2, 569-573.

Manuscript received: May 18, 2021

Revised manuscript received: June 2, 2021

Accepted manuscript online: June 21, 2021

Version of record online: 


\section{Research Articles}

\section{Biobased Polymers}

H. Fouilloux, W. Qiang, C. Robert,

V. Placet, C. M. Thomas* - III-UII

Multicatalytic Transformation of

(Meth)acrylic Acids: a One-Pot Approach

to Biobased Poly (meth)acrylates

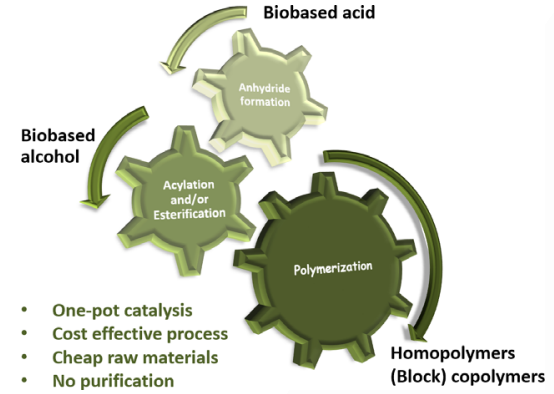

We have developed a multicatalytic approach for the one-pot production of (meth)acrylate monomers, allowing the formation of the corresponding (co) polymers from renewable feedstocks. This highly efficient strategy allowed us to perform multiple catalytic trans-

formations in one pot, while bypassing several purification steps. This procedure can therefore minimize chemical waste, save time, and simplify practicalities.

\section{Biobased Polymers}

H. Fouilloux, W. Qiang, C. Robert, V. Placet, C. M. Thomas* III-IIII

Multicatalytic Transformation of (Meth)acrylic Acids: a One-Pot Approach to Biobased Poly (meth)acrylates

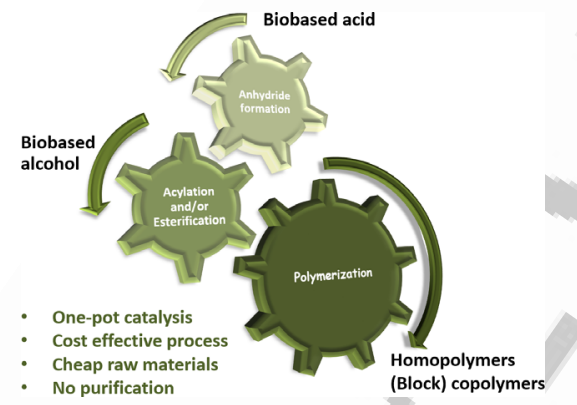

We have developed a multicatalytic approach for the one-pot production of (meth)acrylate monomers, allowing the formation of the corresponding (co)polymers from renewable feedstocks. This highly efficient strategy allowed us to perform multiple catalytic transformations in one pot, while bypassing several purification steps. This procedure can therefore minimize chemical waste, save time, and simplify practicalities.

@IRCP_Polymer @ThomasPolymer SPACE RESERVED FOR IMAGE AND LINK

Share your work on social media! Angewandte Chemie has added Twitter as a means to promote your article. Twitter is an online microblogging service that enables its users to send and read short messages and media, known as tweets. Please check the pre-written tweet in the galley proofs for accuracy. If you, your team, or institution have a Twitter account, please include its handle @username. Please use hashtags only for the most important keywords, such as \#catalysis, \#nanoparticles, or \#proteindesign. The ToC picture and a link to your article will be added automatically, so the tweet text must not exceed 250 characters. This tweet will be posted on the journal's Twitter account (follow us @angew_chem) upon publication of your article in its final (possibly unpaginated) form. We recommend you to re-tweet it to alert more researchers about your publication, or to point it out to your institution's social media team.

Please check that the ORCID identifiers listed below are correct. We encourage all authors to provide an ORCID identifier for each coauthor. ORCID is a registry that provides researchers with a unique digital identifier. Some funding agencies recommend or even require the inclusion of ORCID IDs in all published articles, and authors should consult their funding agency guidelines for details. Registration is easy and free; for further information, see http://orcid.org/.

Hugo Fouilloux http://orcid.org/0000-0003-4270-085X

Dr. Wei Qiang

Dr. Carine Robert http://orcid.org/0000-0003-3497-9846

Dr. Vincent Placet

Prof. Christophe M. Thomas http://orcid.org/0000-0001-8014-4255 